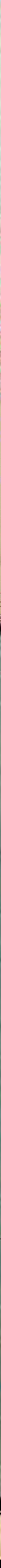




\section{FLIGHT OF THE AIR SHIP}

I NTERM EZZ O

Allegretto
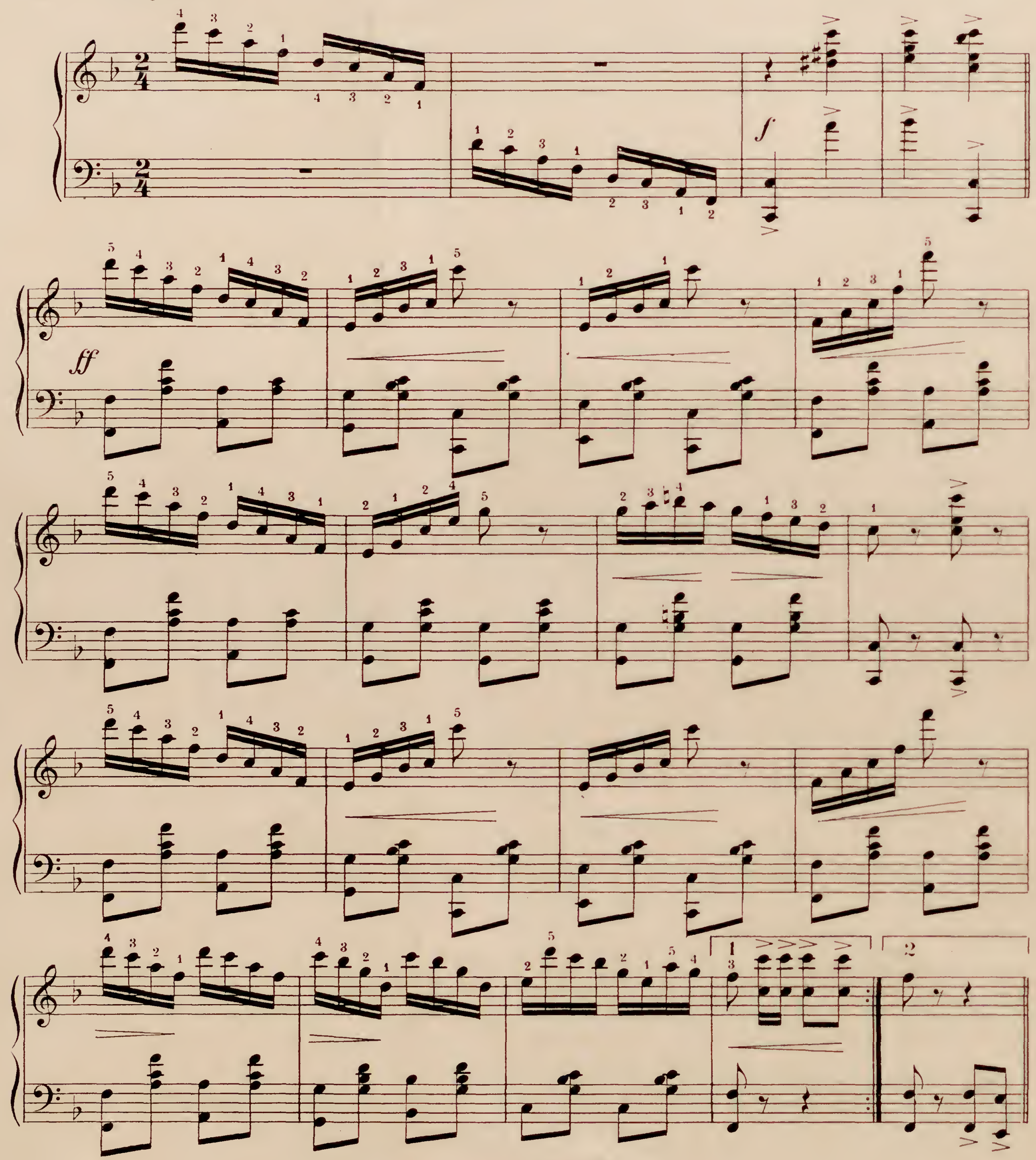

$1177 \quad 4 \quad 1$

Copyright MCMVlll by Mc Kinley Music Co. 

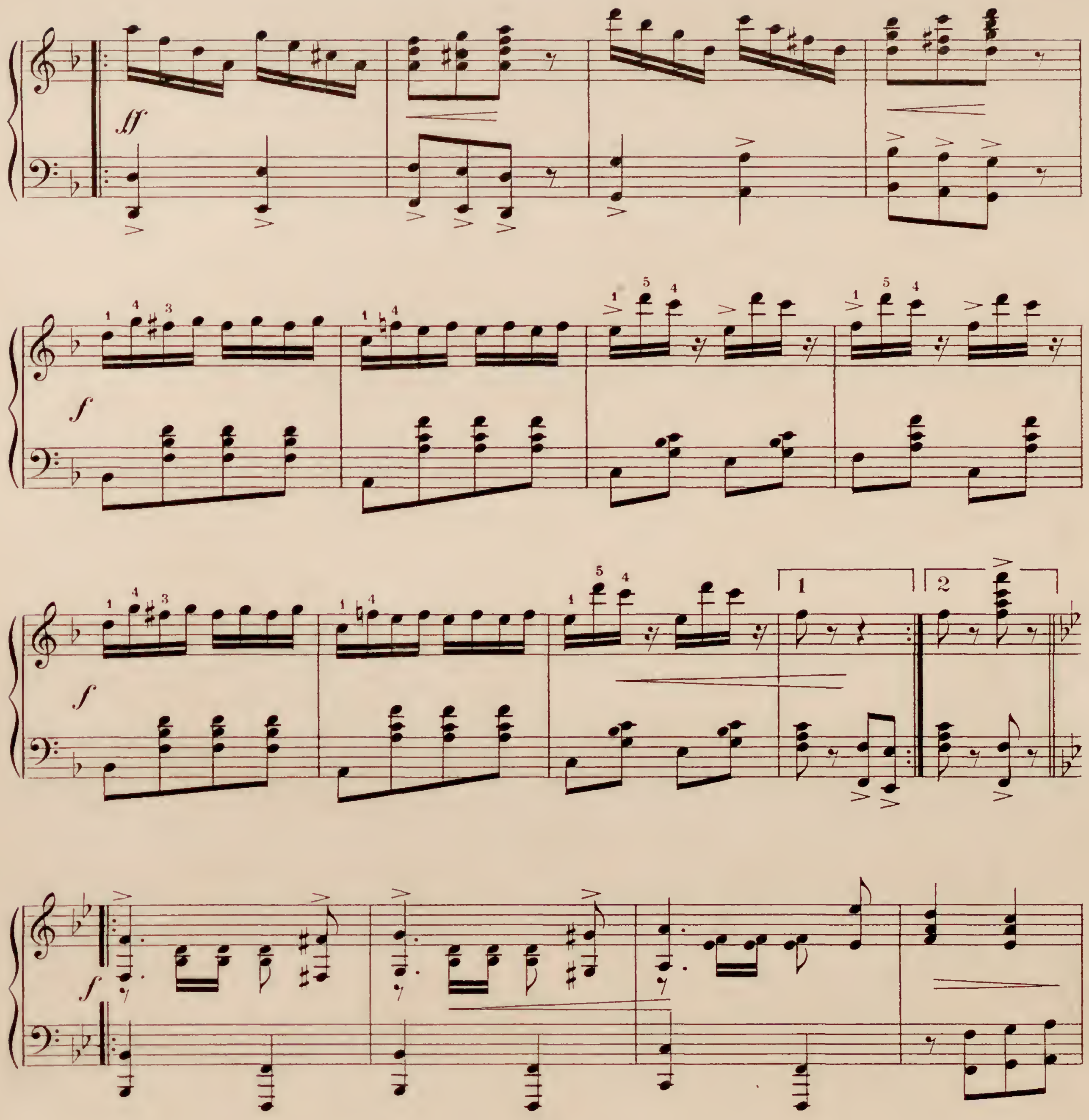

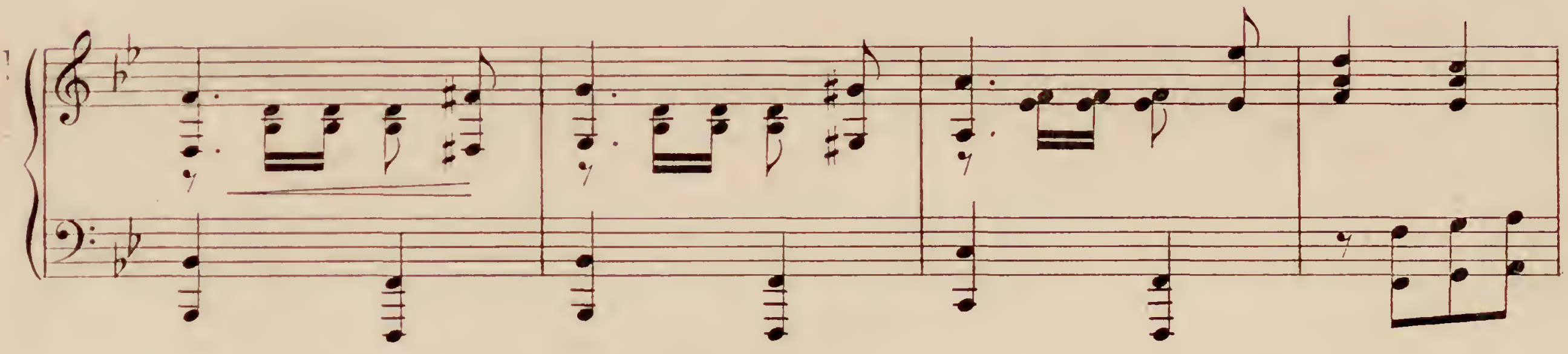
$117+2$ 

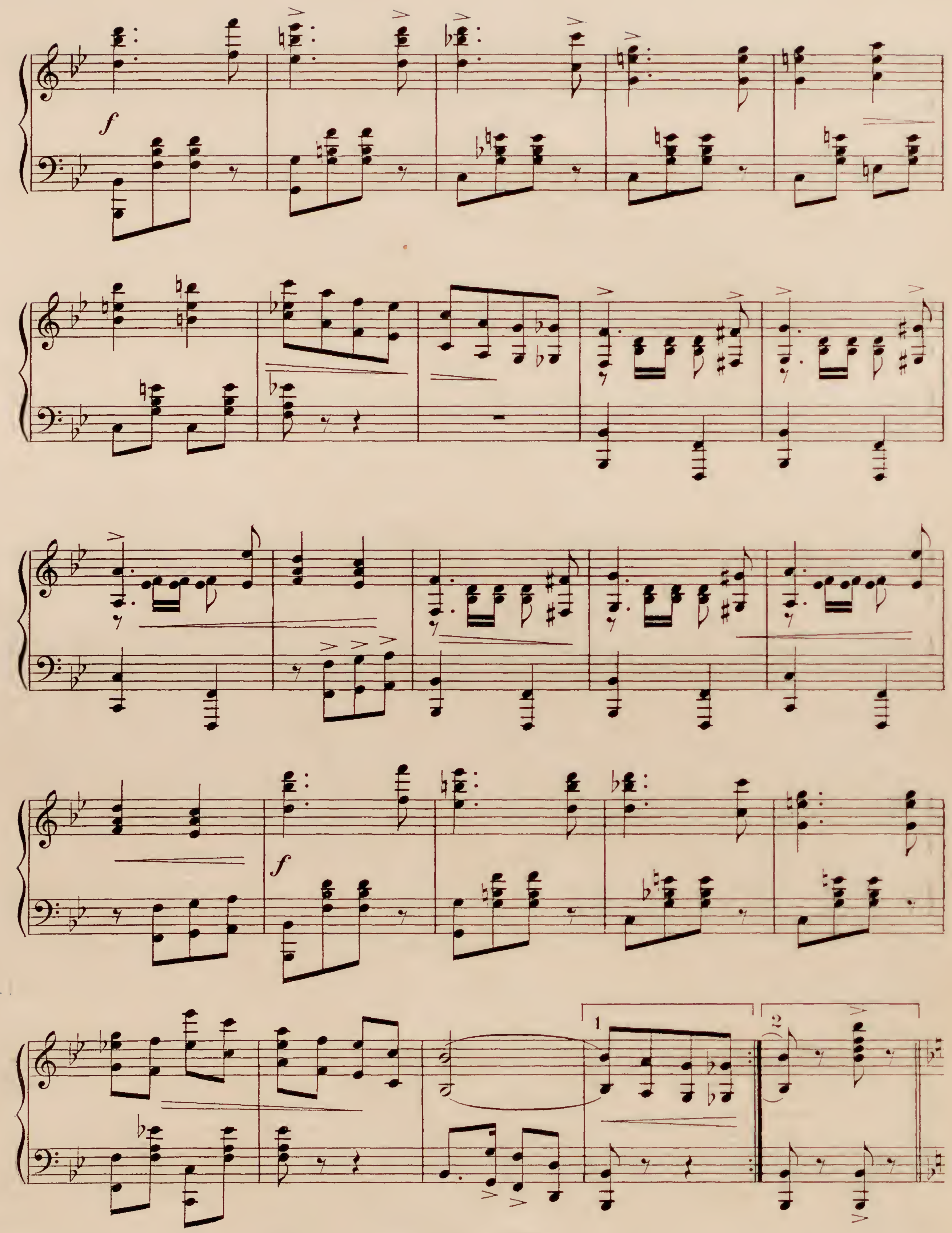

$1177 \quad 4 \quad 3$ 

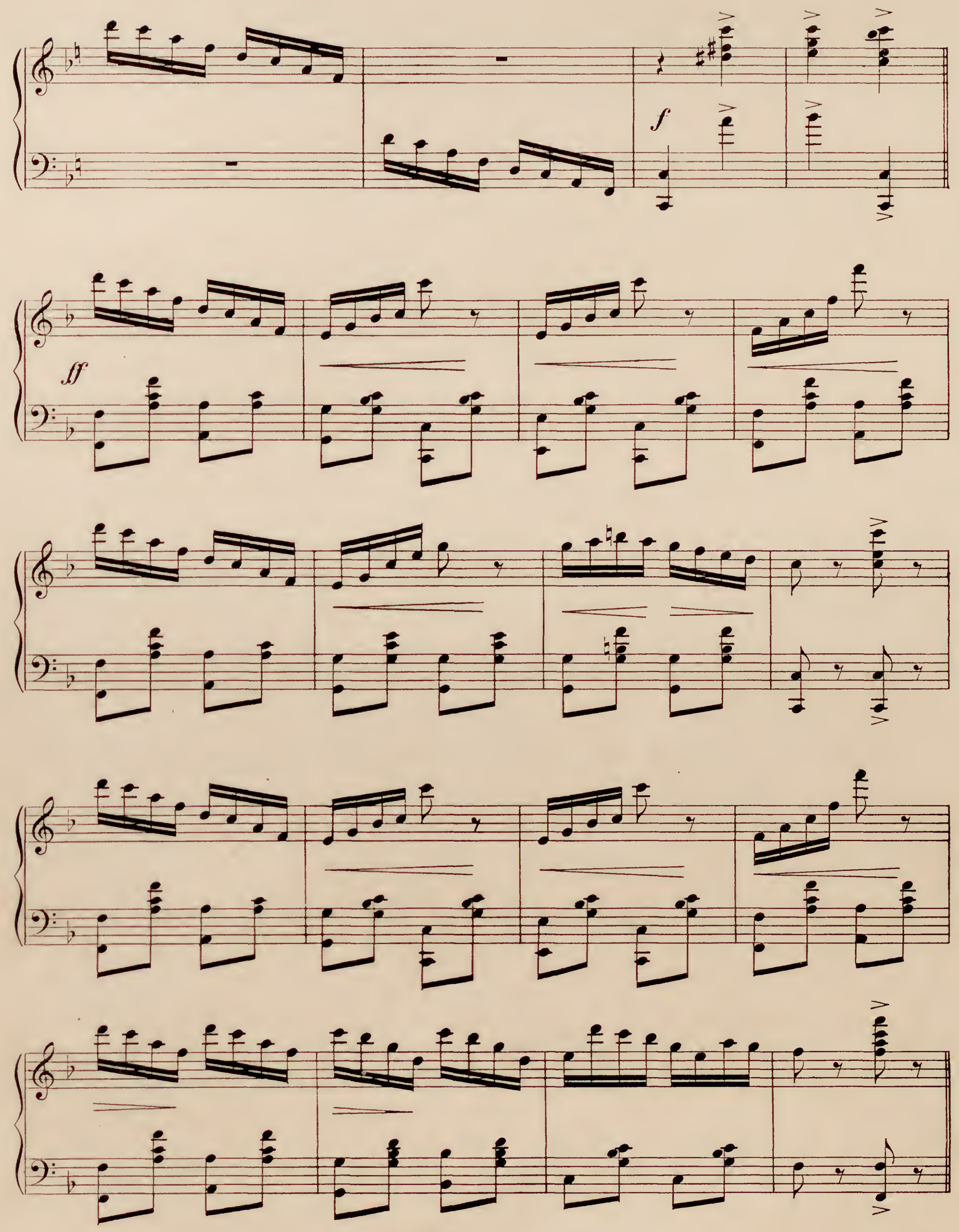


\section{THE FOUR MOST POPULAR PIEOES OF THE YEAR}

Words by ROLL ON THE ROLLAWAY

Chorus

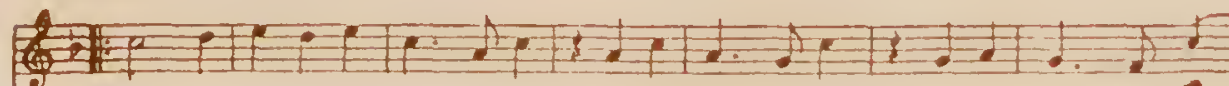

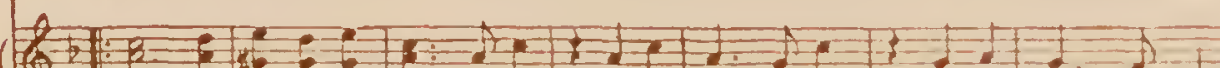

$\left\{\begin{array}{l}\mu-s \\ \hline\end{array}\right.$

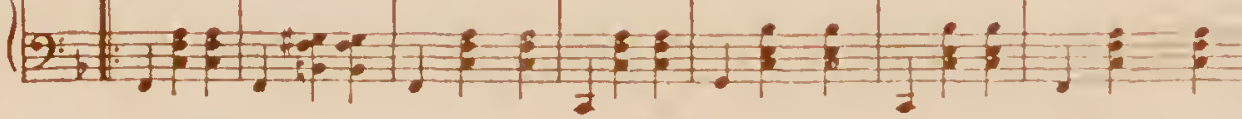

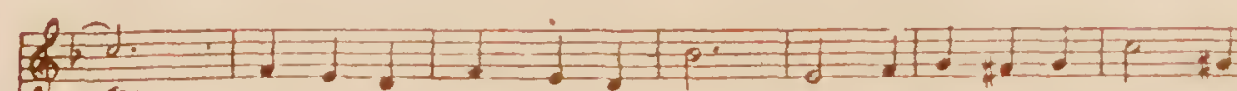

(2) Roll me a - round to the mu - sic, No mat-ter what tune they

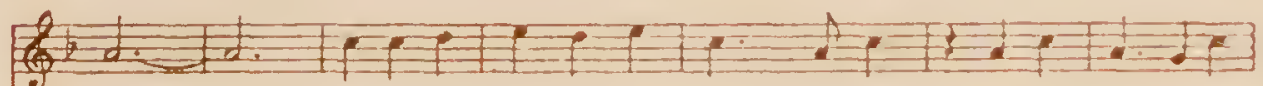

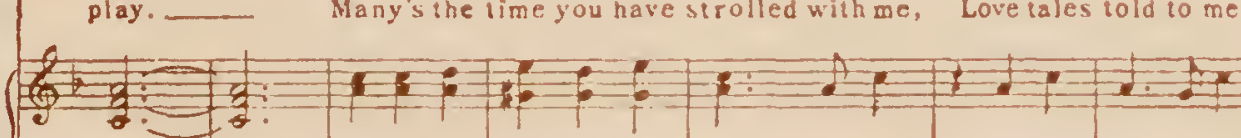

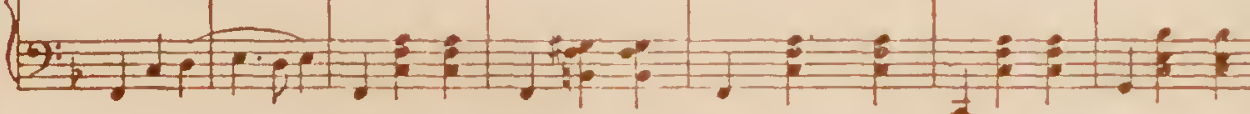

एद.

But hey're old to me; - Comet let's bo gay while the mu - sto thes

Copyright MCMVuI by Mc Kinley Music Co.

HOW'DY HIRAM

HOW'DY HIRAM
Soderato.

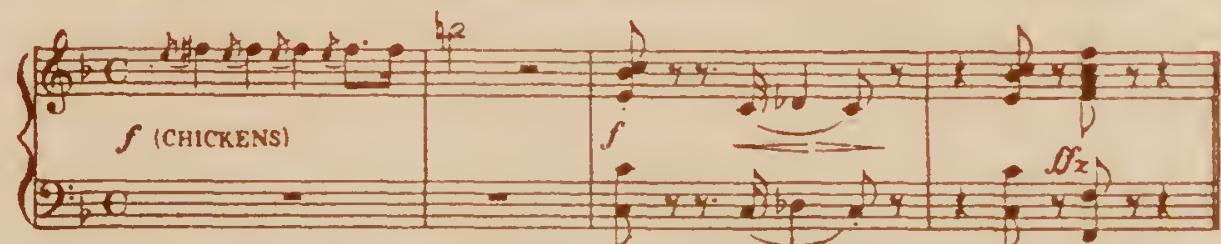

$\left\{\begin{array}{lll}\text { Schottische Ilme. } \\ 5\end{array}\right.$
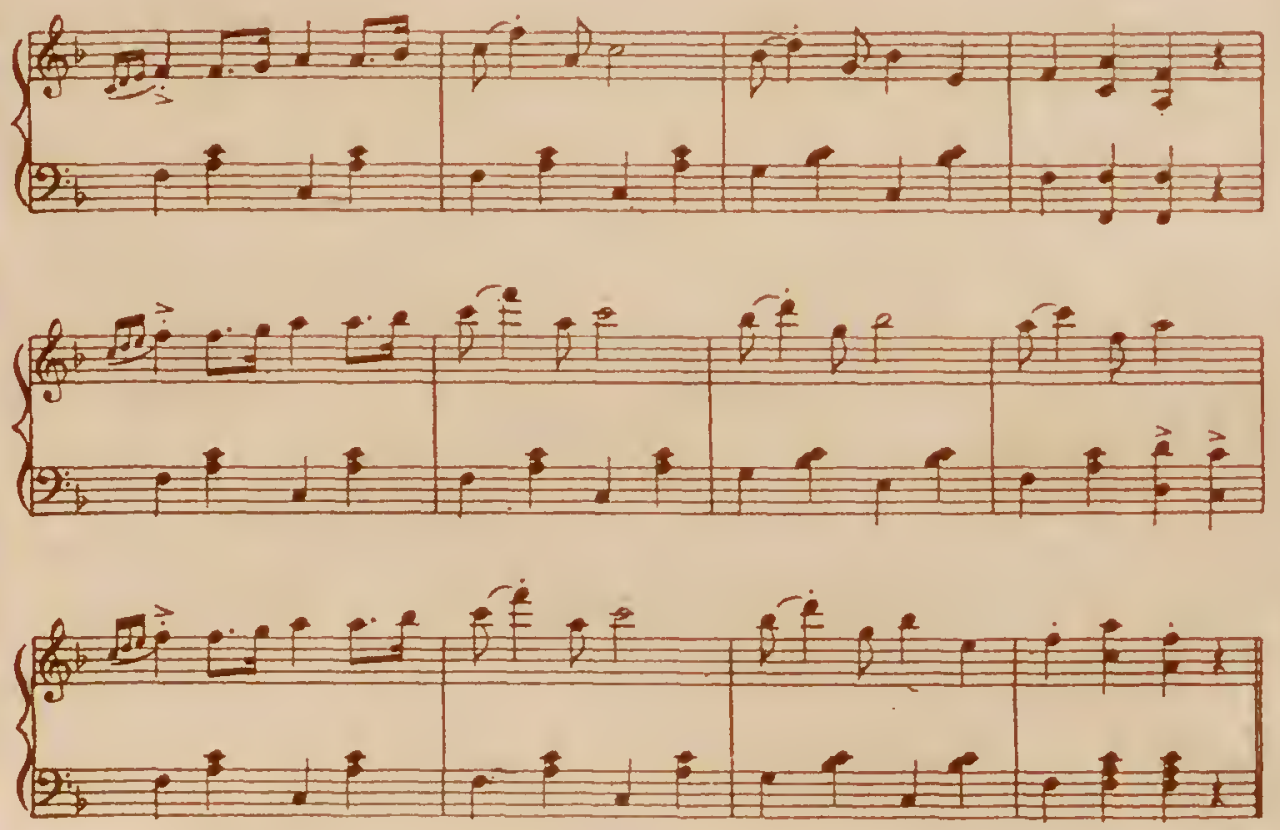

Any of the above pieces sent upon receipt of $25 \mathrm{c}$. Ask your music dealer for them.
LOVE RULES THE WORI.D

REFRAIN.

\& Maestoso.

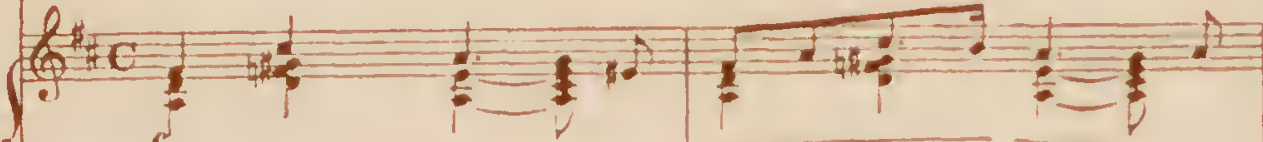

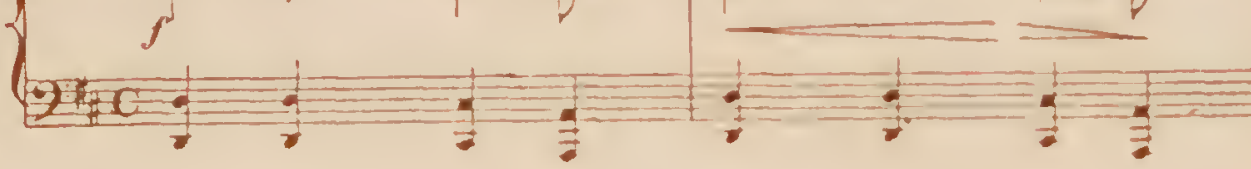

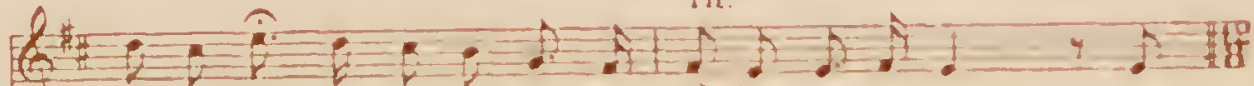

(6)

(F)

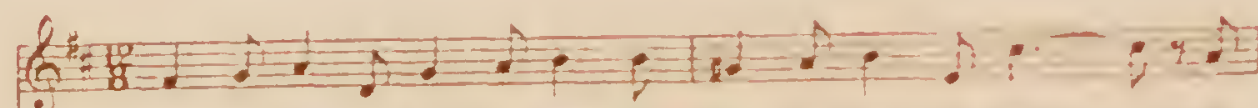

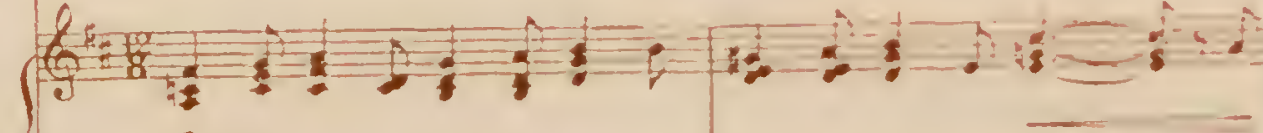

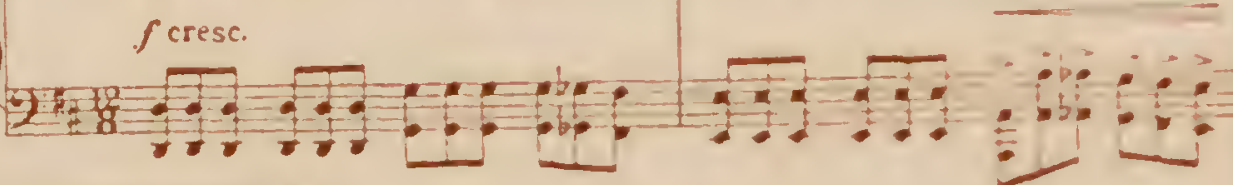
Love tibles the world. 4.9

Copyrighe MCMvill by MiRinley Music Co.

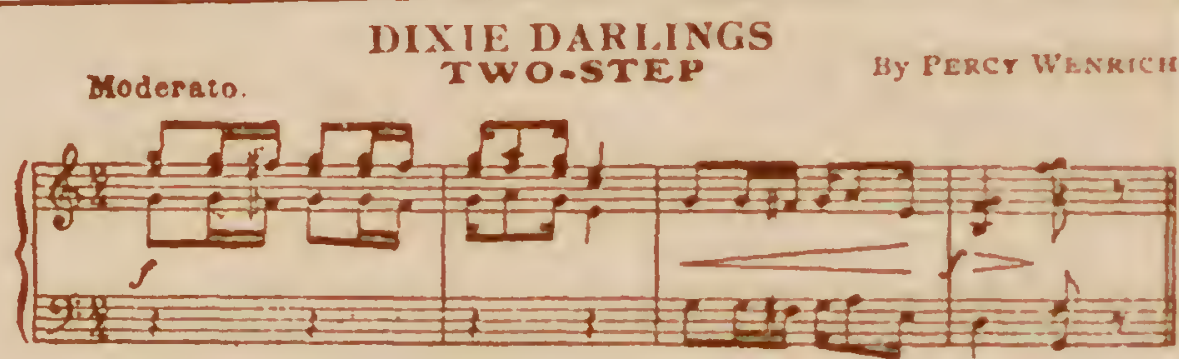

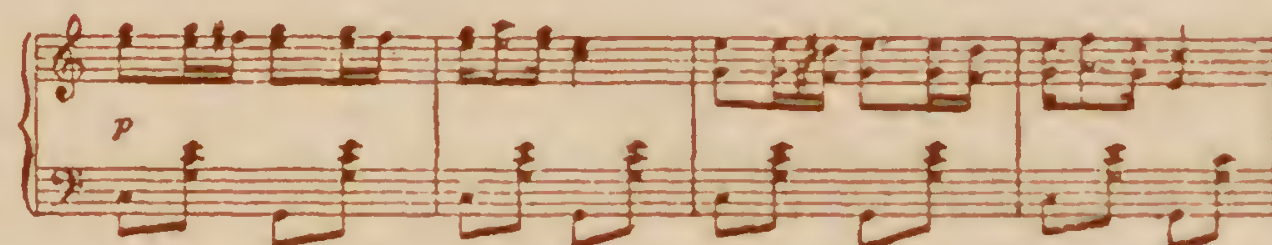

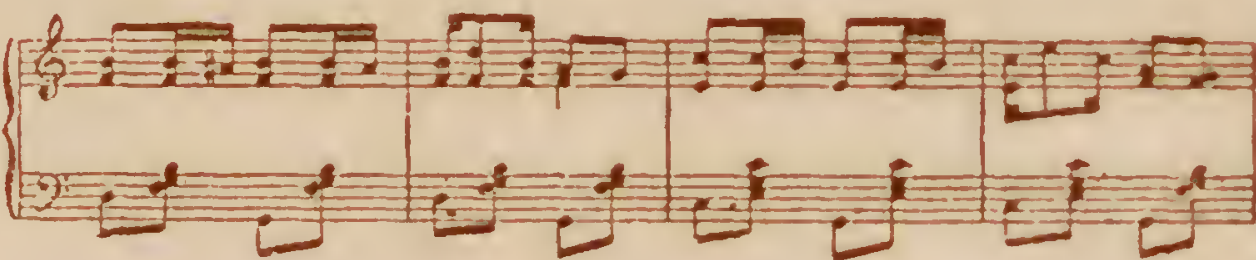

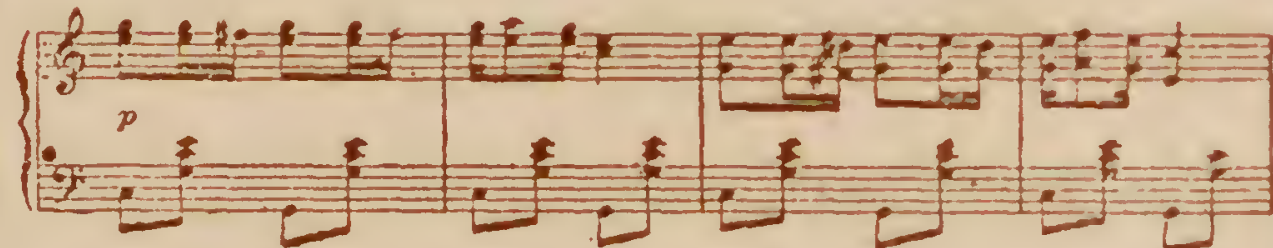

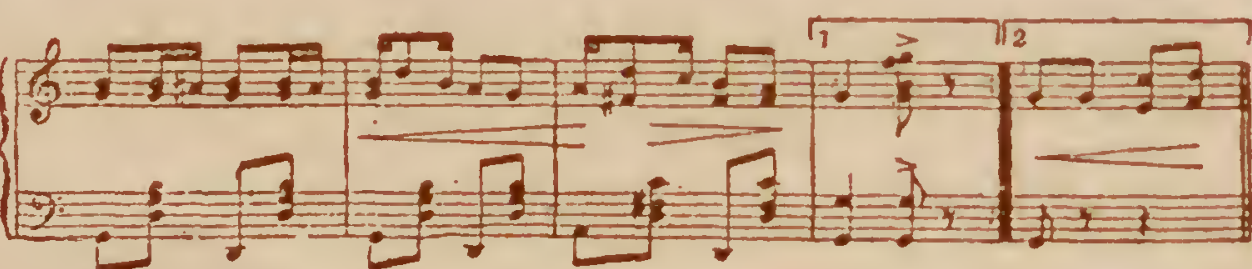
Cepynght, MCMVD, oy we Kinsey Munc Co. Crucare on. 